\title{
IMPLANTAÇÃO DA POLÍTICA NACIONAL DE SAÚDE INTEGRAL DA POPULAÇÃO NEGRA: UM ESTUDO DE AVALIABILIDADE
}

\author{
Filipe das Mercês Ramos da Silva'; Silvone Santa Bárbara da Silva Santos ${ }^{2}$ \\ 1. Estagiário PEVIC, Graduando em Medicina, Universidade Estadual de Feira de Santana, e-mail: felipefsa11@ @otmail.com \\ 2. Orientadora, Departamento de Saúde, Universidade Estadual de Feira de Santana, e-mail: \\ silvone.santabarbara@gmail.com
}

PALAVRAS-CHAVE: Avaliação em Saúde; Política de Saúde; População Negra.

\section{INTRODUÇÃO}

A população negra abrange, segundo o censo de 2010, cerca de $51 \%$ da população brasileira. No entanto, mesmo representado uma parcela significativa do contingente populacional brasileiro, pretos e pardos ainda sofrem com as consequências das desigualdades sociais resultantes do processo de constituição e desenvolvimento desta civilização. Tais desigualdades se manifestam de diversas maneiras, como no baixo nível de escolaridade, nas altas taxas de desemprego e nas suas precárias condições de saúde (OLIVEIRA,2004).

Após anos de luta pela democratização da saúde, o Conselho Nacional de Saúde aprovou, em 2007, a Política Nacional de Saúde Integral da População Negra (PNSIPN), cujo objetivo é garantir a equidade na efetivação do direito humano à saúde em seus aspectos de promoção, prevenção, atenção, tratamento e recuperação de doenças e agravos transmissíveis e não transmissíveis (BRASIL, 2007).

Percebe-se então que a PNSIPN necessita ser avaliada para que sejam esclarecidos os pontos positivos e as fragilidades da mesma. Neste contexto, o objetivo deste trabalho foi realizar um estudo de avaliabilidade sobre a implantação da Política Nacional de Saúde Integral da População Negra, principalmente no estado da Bahia.

\section{MATERIAL E MÉTODOS}

Trata-se de um estudo de avaliabilidade que permitiu analisar a plausibilidade da construção de um modelo avaliativo da Política Nacional de Saúde Integral da População Negra (PNSIPN), por meio da montagem de um esquema de pré-avaliação da mesma. Optou-se por um delineamento exploratório qualitativo, do tipo análise documental, tendo em vista as fontes que seriam úteis para o desenvolvimento do trabalho.

A coleta de dados ocorreu entre o período de setembro de 2016 e abril de 2017, por meio: a) da análise de documentos legais sobre a política, tais como a Portaria $\mathrm{n}^{\circ}$ 992, DE 13 de maio de 2009 que institui a PNSIPN e as cartilhas publicadas pelo Ministério da Saúde; b) da revisão do plano de indicadores elaborado no projeto de pesquisa intitulado "AVALIAÇÃO DA ATENÇÃO À SAÚDE DA POPULAÇÃO NEGRA E A INTERSECÇÃO DO RACISMO SOBRE AS PRÁTICAS DE CUIDADO EM ESTADOS DO NORDESTE E DO SUDESTE BRASILEIRO", financiada pelo CNPq; c) de reuniões com informantes-chave, identificados na fase exploratória da pesquisa.

\section{RESULTADOS E DISCUSSÃO}

A avaliação dos documentos legais revela que o objetivo principal da PNSIPN é reduzir as desigualdades étnico-raciais e promover o combate ao racismo institucional no SUS.

O plano de indicadores, presente no já referido projeto, demonstrou ser um instrumento útil e relevante nesse processo de pré-avaliação, sendo um dos componentes fundamentais do modelo lógico descrito mais adiante. Ferreira, Cassiolato e Gonzalez (2009) partem do pressuposto que o indicador é uma medida de ordem quantitativa ou qualitativa, cuja função é 
apreender informações importantes sobre o objeto estudado. Para tornar viável a aplicação dos indicadores, o plano leva em consideração a existência de três dimensões de análise, distintas porém indissociáveis: a dimensão da atenção à saúde, a dimensão da gestão e a dimensão do ensino e pesquisa. Cada dimensão contempla determinada quantidade de indicadores dispostos em varáveis específicas, como pode ser observado na Tabela 1.

Tabela 1: Distribuição dos indicadores nas diferentes dimensões de análise

\begin{tabular}{|c|c|c|c|}
\hline & & VARIÁVEL & INDICADOR \\
\hline \multirow{11}{*}{ I. } & \multirow{11}{*}{$\begin{array}{lr}\text { Dimensão } & \text { da } \\
\text { Atenção } & \text { à } \\
\text { Saúde } & \end{array}$} & \multirow[b]{2}{*}{ Assistência pré-natal } & $\begin{array}{l}\text { \% de assistência pré-natal nas } \\
\text { mulheres negras }\end{array}$ \\
\hline & & & $\begin{array}{l}\% \text { de exames realizados pelas } \\
\text { mulheres definidos na consulta } \\
\text { pré-natal }\end{array}$ \\
\hline & & \multirow{2}{*}{$\begin{array}{l}\text { Comitê de vigilância a } \\
\text { mortalidade materna }\end{array}$} & $\begin{array}{l}\text { Implantação de comitê de } \\
\text { mortalidade materna }\end{array}$ \\
\hline & & & $\begin{array}{l}\text { Comitê de mortalidade materna } \\
\text { realizando as investigações }\end{array}$ \\
\hline & & $\begin{array}{c}\text { Criação de instância de } \\
\text { promoção da equidade em } \\
\text { saúde }\end{array}$ & $\begin{array}{l}\text { Implantação de instância de } \\
\text { promoção da equidade em saúde }\end{array}$ \\
\hline & & $\begin{array}{c}\text { Vigilância de violência e } \\
\text { acidentes }\end{array}$ & $\begin{array}{l}\text { Implantação de vigilância de } \\
\text { violência e acidentes }\end{array}$ \\
\hline & & \multirow[b]{2}{*}{$\begin{array}{l}\text { Mortalidade infantil pós- } \\
\text { neonatal por doenças diarreicas } \\
\text { e pneumonia }\end{array}$} & $\begin{array}{l}\text { Vigilância de óbito infantil na } \\
\text { população negra }\end{array}$ \\
\hline & & & $\begin{array}{l}\text { Razão: mortalidade por doenças } \\
\text { diarreicas e pneumonia na } \\
\text { população negra na infância / total } \\
\text { de óbitos na infância pelo mesmo } \\
\text { grupo de causas }\end{array}$ \\
\hline & & $\begin{array}{l}\text { Atenção às pessoas com } \\
\text { Doença Falciforme }\end{array}$ & $\begin{array}{lll}\text { Unidade de Saúde } & \text { com } \\
\text { atendimento às pessoas } & \text { com } \\
\text { Doença Falciforme } & & \end{array}$ \\
\hline & & $\begin{array}{c}\text { Desenvolvimento de ações de } \\
\text { saúde em áreas remanescentes } \\
\text { de Quilombos }\end{array}$ & $\begin{array}{ll}\text { Ações desenvolvidas em } \\
\text { Comunidades Quilombolas }\end{array}$ \\
\hline & & $\begin{array}{l}\text { Desenvolvimento de ações de } \\
\text { saúde junto à Comunidades } \\
\text { tradicionais de Matriz Africana }\end{array}$ & $\begin{array}{l}\text { Ações desenvolvidas com } \\
\text { Comunidades Tradicionais de } \\
\text { Matriz Africana }\end{array}$ \\
\hline & \multirow{3}{*}{$\begin{array}{l}\text { Dimensão da } \\
\text { Gestão }\end{array}$} & \multirow{3}{*}{ Controle Social } & $\begin{array}{l}\text { Representantes } \\
\text { negras como conselheiros de } \\
\text { saúde }\end{array}$ \\
\hline & & & $\begin{array}{l}\text { Conselheiros participando da } \\
\text { elaboração de planos e projetos } \\
\text { voltados para a saúde da } \\
\text { população negra }\end{array}$ \\
\hline & & & $\begin{array}{l}\text { Projeto ou plano de ação voltado } \\
\text { para a população negra } \\
\text { apresentado no non conselho } \\
\text { municipal de saúde }\end{array}$ \\
\hline
\end{tabular}




\begin{tabular}{|c|c|c|c|}
\hline & & \multirow[t]{2}{*}{ Processo decisório } & $\begin{array}{l}\text { Processo decisório baseado nas } \\
\text { diretrizes propostas no Plano } \\
\text { Municipal de Saúde }\end{array}$ \\
\hline & & & $\begin{array}{l}\text { Existência de instância de } \\
\text { promoção de equidade em saúde }\end{array}$ \\
\hline \multirow[t]{2}{*}{ III. } & \multirow{2}{*}{$\begin{array}{l}\text { Dimensão do } \\
\text { Ensino e } \\
\text { Pesquisa }\end{array}$} & $\begin{array}{l}\text { Introdução da abordagem } \\
\text { étnico-racial nos processos de } \\
\text { formação das instituições } \\
\text { públicas de ensino superior }\end{array}$ & $\begin{array}{l}\text { Presença de disciplinas que } \\
\text { contemplem a abordagem étnico } \\
\text { racial na grade curricular dos } \\
\text { cursos de saúde }\end{array}$ \\
\hline & & $\begin{array}{l}\text { Produção bibliográfica sobre a } \\
\text { Saúde da População Negra }\end{array}$ & $\begin{array}{l}\text { Produção bibliográfica sobre a } \\
\text { Saúde da População Negra no } \\
\text { Brasil e na Bahia }\end{array}$ \\
\hline
\end{tabular}

Fonte: Plano de indicadores do projeto "Avaliação da Atenção à Saúde da População Negra e a Intersecção do Racismo Sobre as Práticas de Cuidado em Estados do Nordeste e do Sudeste Brasileiro"

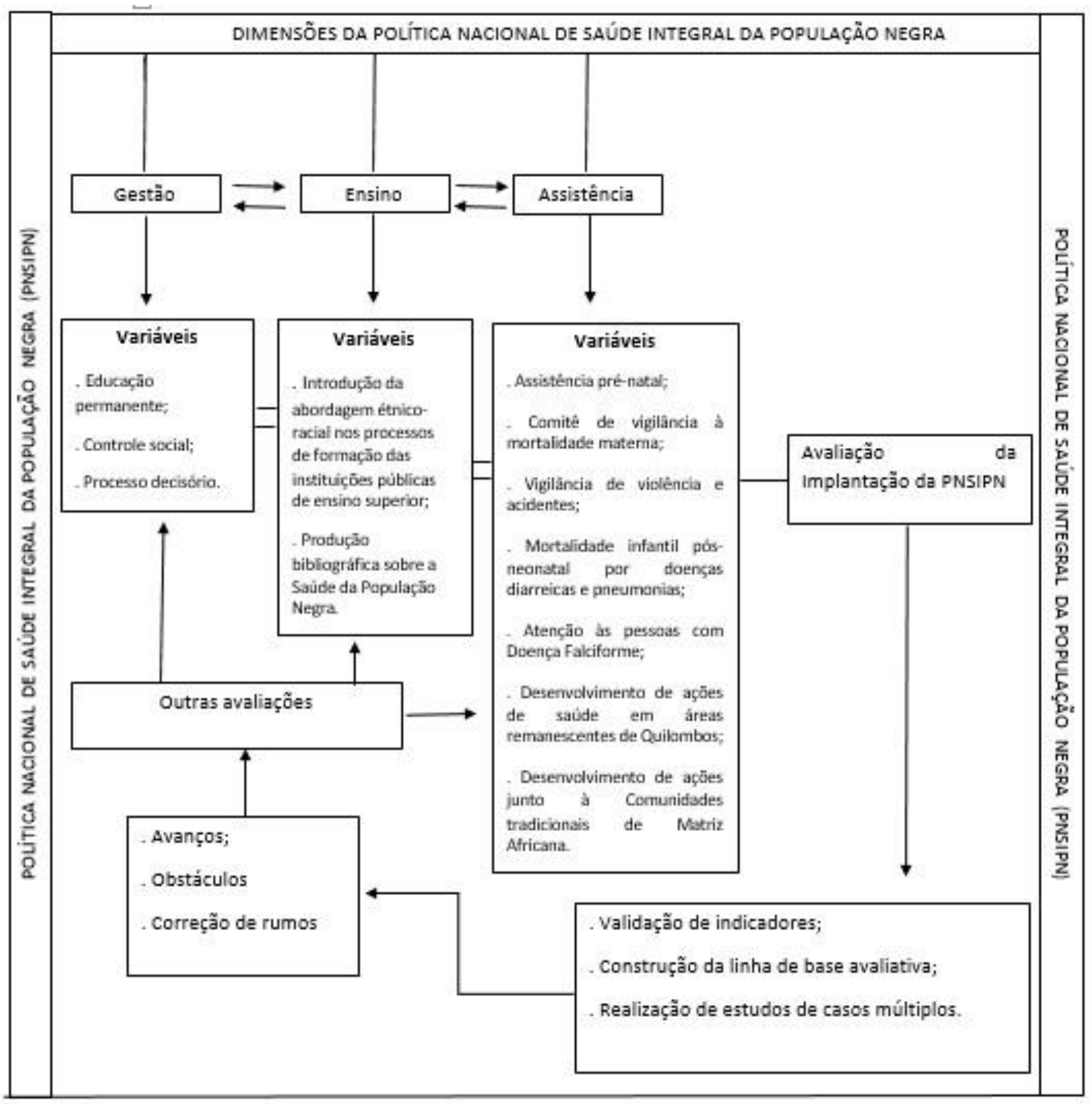

Figura 1: Modelo lógico para estudo de avaliabilidade da PNSIPN 
A reunião com os experts na temática, permitiu uma discussão mais aprofundada sobre o plano de indicadores, acrescentando-se variáveis e indicadores considerados fundamentais e retirados outros, que segundo análise desse grupo, não iria interferir na avaliação da implantação da Política de Atenção à saúde da População Negra.

A criação de um modelo lógico da PNSIPN (figura 1), resultado desse trabalho, possibilitou caracterizar o processo de avaliação, sinalizando para a importância, utilidade e oportunidade da avaliação dessa política. Através deste estudo, será possível maximizar a etapa da avaliação propriamente dita, direcionando para as dimensões e variáveis que permitirá a emissão de um juízo de valor, podendo direcionar para um processo de tomada de decisão e correção de rumos. Preceder a avaliação com este tipo de estudo também maximiza os recursos que serão utilizados, nas avaliações formais.

\section{CONSIDERAÇÕES FINAIS}

Conclui-se que é possível avaliar a PNSIPN nas três dimensões definidas previamente, sendo necessário, no entanto, a validação desses indicadores a partir da participação de expertises na área da saúde da população negra, da avaliação de políticas e na área de psicometria e linguística.

O desenvolvimento do modelo teórico da avaliação, a partir deste estudo, permitirá subsidiar avaliações futuras e correções de rumos.

\section{REFERÊNCIAS}

BRASIL. Ministério da Saúde (MS). Política Nacional de Saúde Integral da População Negra. Brasília: MS; 2007.

OLIVEIRA, M.; FIGUEIREDO, N. D. Critica sobre políticas, ações e programas de saúde implementados no Brasil. In: LOPES, F. (Org.). Saúde da População Negra no Brasil: contribuições para a promoção da equidade [relatório Final -Convênio UNESCO projeto 914BRA3002]. Brasília: Funasa/MS, 2004.

FERREIRA, H.; CASSIOLATO, M.; GONZALEZ, R. Como elaborar Modelo Lógico de programa: um roteiro básico. Brasília: 2007. Disponível em:

<http://agencia.ipea.gov.br/images/stories/PDFs/TDs/td_1369.pdf>. Acesso em: 14 set 2017. 